\title{
Histomorphological Evaluation of Colonoscopic Mucosal Biopsy with Chronic Gastrointestinal Disorders
}

\author{
Karim $\mathrm{MI}^{1}$, Nachev $\mathrm{R}^{2}$, Fuklev $\mathrm{N}^{3}$, Wahab $\mathrm{MA}^{4}$ \\ DOI: https://doi.org/10.3329/jafmc.v13i2.41377
}

\begin{abstract}
Introduction: Colonoscopic biopsy is important in the diagnosis and treatment of suspected colonic diseases as it is a diagnostic procedure of choice for patients with gastrointestinal disorders lasting for several weeks to months. Histomorphological evaluation of colonic biopsy is important for specific diagnosis, for determining the extent of the disease and its response to therapy and for detecting complications.
\end{abstract}

Objective: To evaluate colorectal mucosal lesion by histopathological examination and to confirm the diagnosis of different gastrointestinal diseases including malignancies.

Materials and Methods: This descriptive cross-sectional study was conducted on 330 colonoscopic biopsies with different gastrointestinal disorders from January 2014 to December 2016 in the Department of Pathology, Armed Forces Hospital, Kuwait.

Results: About $75.2 \%$ of cases were male with average age was 45 years with ranging 10-80 years. Out of 330 biopsies specific diagnosis was made in $63 \%$ cases and among the specific diagnosis, tubular adenoma was the commonest (21.22\%) followed by inflammatory bowel diseases $13.94 \%$ cases. Total malignant cases were $7.60 \%$ and majority of them in the age group of 41-60 years.

Conclusion: The importance of colonoscopic biopsies lies especially in some chronic diarrhoea, alteration of bowel habit and per rectal bleeding. Moreover with the early histopathological diagnosis by detecting the precancerous lesion, like Ulcerative colitis, adenomatous polyp, patient can get rid of developing cancer and thereby saved life.

Key-words: Colonoscopy, Inflammatory bowel diseases, Colitis, Neoplasia.

\section{Introduction}

Since 1970, Colonscopy is one of the most important tools to evaluate the large bowel and to screen colorectal diseases, especially neoplasia and polyps ${ }^{1}$. It also makes it possible to identify early lesions in risk groups, to investigate signs and

symptoms of abdominal pain, gastrointestinal bleeding, changes in bowel habits, chronic diarrhoea, unexplained refractory iron deficiency anemia and abdominal masses to follow up the patients treated for colorectal cancer or inflammatory bowel disease $^{2}$. Through colonoscopy, it is possible to visualize the mucosa of the terminal ileum, colon and rectum and to check for macroscopic lesions ${ }^{3}$. In addition, several procedures can be performed, especially biopsies. The introduction of associated technologies, such as chromoscopy and image magnification has extended the use colonoscopy, making it easier to identify subtle lesions and benefiting a greater number of patients ${ }^{4}$. In fact, colonoscopy is currently one of the most complete tools for colorectal disease investigation ${ }^{5}$.

Examination of colorectal biopsy specimen is a reliable method for diagnosing inflammatory bowel disease ${ }^{6}$ though many factors lead to variation in biopsy interpretation between reporting histopathologists ${ }^{7}$. Passing generations and the accompanying lifestyle changes is associated with an increased incidence of gastrointestinal diseases. Epithelial tumors of colon are a major cause of morbidity and mortality worldwide. Colorectal cancer is the fourth ranking cancer worldwide, accounting for approximately $9 \%$ of all cancers ${ }^{8}$. Adenocarcinomas are the commonest malignancies arising in the colorectal region, other being carcinoid and melanoma. Colonoscopy is currently considered to be gold standard for cancer surveillance ${ }^{9}$. The development of fibre-optic colonoscope has enabled the clinician to visualize the mucosa of the rectum, entire colon and terminal ileum, to screen the intestinal abnormalities and to get representative biopsy for the definitive diagnosis ${ }^{10}$. Histomorphological examinations of colorectal biopsies reveal a spectrum of lesions ranging from non-neoplastic lesion to neoplastic tumours including benign and malignant tumour. All these lesions often require colonoscopic biopsies for their conclusive diagnosis ${ }^{11}$. Both macroscopic and microscopic appearance along with clinical correlation helps in definitive diagnosis of the lesion which helps in early treatment and better outcome of the patient. The objective of the study is to evaluate colorectal mucosal lesions by histopathological examination and to confirm the diagnosis of different gastrointestinal diseases including malignancies.

1. Lt Col Md Iqbal Karim, MBBS, MCPS, DCP, FCPS, Classified Specialist in Pathology, OKP-5, Kuwait 2. Dr Rosen Nachev, MBBS, MD, Consultant Histopathology, Armed Forces Hospital, Kuwait 3. Dr Nikolay Fuklev, MBBS, MD, Consultant Histopathology, Armed Forces Hospital, Kuwait 4. Lt Col Md Abdul Wahab, MBBS, MD, Associate Professor of Biochemistry, AFMC, Dhaka. 


\section{Materials and Methods}

This descriptive cross-sectional study was conducted on 330 biopsies from patients attending the Gastroenterology OPD who presented with lower gastrointestinal tract symptoms. Information was retrieved from digital clinical records at Jaber Al Ahmed Armed Forces Hospital, Kuwait covering the period January 2014 to December 2016. Clinical details along with a detailed description of the colonoscopic findings were obtained. An attempt was made by the clinician to give a colonoscopic diagnosis in all the cases. The samples were collected in 10\% neutral buffered formalin processed and embedded in paraffin with the mucosal surface being uppermost and $4 \mu$ thick serial sections were prepared. All tissues were stained with $\mathrm{H} \& \mathrm{E}$ and special stains like Periodic Acid Schiff (PAS), Alcian blue (PAS/Alb), Reticulin, Ziehl Nielsen (ZN) along with Immunohistochemistry (IHC) such as cytokeratin(CK), Mucicarmin (MUC) for colorectal adenocarcinoma, Chromogranin and synaptophysin for neuroendocrine tumour were done as and when required. The diagnosis of colorectal biopsies was made on the basis of clinical presentation, colonoscopic findings and light microscopic features of H\&E and special stained sections. The lesions were classified as non-neoplastic lesions, benign neoplastic lesions and malignant tumors. The tumors were classified as per WHO classification and observations were compared with other studies. Statistical analysis was done by software SPSS version 17.0. Categorical variables are expressed as frequencies and percentages. Chi-square test was done and $p<0.05$ was considered statistically significant.

\section{Results}

Biopsies were performed on patients of all age groups with complains of gastrointestinal disorders, the youngest was a 10 year old child and oldest was an 85 year old male. Average age was 45 irrespective of age and sex; the overall common symptoms of presentation were altered bowel habits, per rectal bleeding, anaemia, diarrhoea, pain abdomen and colonic ulcer, mass or growth. However, most of the patients had more than one symptom during presentation. In Table-l shows diarrhoea $(43.33 \%)$, altered bowel habit (33.64\%) and per rectal bleeding $(11.52 \%)$ were common predominant symptoms.

Table-l: Distribution of patients according to predominant symptoms $(\mathrm{n}=330)$

\begin{tabular}{|l|c|c|}
\hline Symptoms & No of patients & $\mathbf{( \% )}$ \\
\hline Diarrhoea & 143 & $43.33 \%$ \\
\hline Altered bowel habit & 111 & $33.64 \%$ \\
\hline Pain abdomen & 28 & $8.48 \%$ \\
\hline Per rectal bleeding & 38 & $11.52 \%$ \\
\hline Anaemia & 08 & $2.42 \%$ \\
\hline Intestinal obstruction & 02 & $0.61 \%$ \\
\hline Total & 330 & $100 \%$ \\
\hline
\end{tabular}

Among 330 cases, $248(75.15 \%)$ cases were male and 82 $(24.85 \%)$ were female. Male to female ratio $3: 1$. The type of lesions broadly diagnosed as specific and non specific diagnosis. Specific diagnosis based on definitive changes like tubular adenoma, adenocarcinoma, carcinoid tumour etc. Non specific diagnosis included non specific colitis and no significant histomorphological changes. Specific diagnosis was made in $63 \%$ and nonspecific diagnosis was $37 \%$ cases (Table-II).

Table-II: Age and sex distribution of histopathological diagnosis of colonic mucosal lesion ( $n=330$ )

\begin{tabular}{|c|c|c|c|c|c|c|c|c|c|}
\hline \multirow{2}{*}{\multicolumn{2}{|c|}{ Type of lesions }} & \multicolumn{2}{|c|}{ SEX } & \multicolumn{4}{|c|}{ Distribution of ages (yrs) } & \multirow{3}{*}{$\begin{array}{c}\mathrm{n}=330 \\
20\end{array}$} & \multirow{3}{*}{$\begin{array}{c}\% \\
6.06 \\
\end{array}$} \\
\hline & & \multirow{2}{*}{$\begin{array}{c}\text { Male } \\
14 \\
\end{array}$} & \multirow{2}{*}{$\begin{array}{c}\text { Female } \\
6\end{array}$} & \multirow{2}{*}{$\begin{array}{c}10-20 \\
10 \\
\end{array}$} & \multirow{2}{*}{$\begin{array}{c}21-40 \\
5 \\
\end{array}$} & \multirow{2}{*}{$\begin{array}{c}41-60 \\
4\end{array}$} & \multirow{2}{*}{$\begin{array}{c}>60 \mathrm{yrs} \\
1\end{array}$} & & \\
\hline Non cnecific changes & No significant changes & & & & & & & & \\
\hline Non specinc ciranges & Nonspecific colitis & 82 & 20 & 18 & 30 & 26 & 28 & 102 & 30.92 \\
\hline \multirow{14}{*}{ Specific diagnosis } & Microscopic colitis & 04 & 02 & 02 & 01 & 02 & 01 & 06 & 1.82 \\
\hline & Ulcerative coilits & 25 & 07 & 02 & 17 & 09 & 04 & 32 & 9.70 \\
\hline & Corhn disease & 9 & 5 & 3 & 7 & 3 & 1 & 14 & 4.24 \\
\hline & Lymphocytic colitis & 02 & 0 & 0 & 02 & 0 & 0 & 02 & 0.60 \\
\hline & Lymphoid hyperplasia & 03 & 01 & 03 & 01 & 0 & 0 & 04 & 1.22 \\
\hline & Hyperplastic polyp & 18 & 04 & 15 & 05 & 02 & 0 & 22 & 6.66 \\
\hline & Tubular adenoma & 54 & 16 & 15 & 16 & 30 & 09 & 70 & 21.22 \\
\hline & Villous adenoma & 06 & 04 & 02 & 03 & 02 & 03 & 10 & 3.03 \\
\hline & Tubulovillous adenoma & 10 & 06 & 02 & 04 & 06 & 04 & 16 & 4.85 \\
\hline & Radiation colitis & 01 & 0 & 0 & 0 & 0 & 01 & 01 & 0.30 \\
\hline & Collagen colitis & 01 & 0 & 0 & 01 & 0 & 0 & 01 & 0.30 \\
\hline & Solitary rectal ulcer & 04 & 01 & 0 & 02 & 02 & 01 & 05 & 1.51 \\
\hline & Adenocarcinoma & 12 & 08 & 01 & 02 & 10 & 07 & 20 & 6.06 \\
\hline & Carcinoid & 03 & 02 & 01 & 02 & 01 & 01 & 05 & 1.51 \\
\hline \multicolumn{2}{|r|}{ Total } & 248 & 82 & 74 & 98 & 97 & 61 & 330 & 100.00 \\
\hline
\end{tabular}


Among 46 cases of IBD 32 of them were Ulcerative colitis, 14 cases were Crohn's disease and 25 cases were found malignant tumor with variable gastrointestinal symptoms. Significant $(p<0.001)$ correlation of gastrointestinal symptoms with crohn's disease, ulcerative colitis and malignant tumor was found (Table-III).

Table-III: Types of lesion related to the predominant symptoms of patient $(n=330)$

\begin{tabular}{|c|c|c|c|c|c|c|}
\hline & $\begin{array}{l}\text { Chronic unexplained } \\
\text { diarrhoea }(n=143)\end{array}$ & $\begin{array}{l}\text { Altered bowel } \\
\text { habit }(n=111)\end{array}$ & $\begin{array}{l}\text { Bleeding per } \\
\text { rectum }(n=38)\end{array}$ & $\begin{array}{c}\text { Others } \\
\text { symptoms (38) }\end{array}$ & Total & Statistics \\
\hline Non Specific colitis & 67 & 20 & 03 & 12 & 102 & \multirow{6}{*}{$\begin{array}{c}\chi^{2}=112.6 \\
d f=12 \\
P<0.001\end{array}$} \\
\hline Inflammatory bowel diseases (UC, CD) & 16 & 21 & 06 & 03 & 46 & \\
\hline Adenomatous polyp & 34 & 31 & 10 & 21 & 96 & \\
\hline Malignant tumor & 04 & 05 & 15 & 01 & 25 & \\
\hline Others lesions & 22 & 34 & 04 & 01 & 61 & \\
\hline Total & 143 & 111 & 38 & 38 & 330 & \\
\hline
\end{tabular}

Out of 330 cases, $20(6.10 \%)$ cases did not show any significant histomorphological changes, $189(57.30 \%)$ were non-neoplastic and $121(36.70 \%)$ were neoplastic lesion where $96(29 \%)$ benign neoplastic polyps and $25(7.60 \%)$ cases were malignant lesion. It was observed that non-neoplastic lesions $(57.30 \%)$ were predominant over neoplastic lesions (Fig-1).

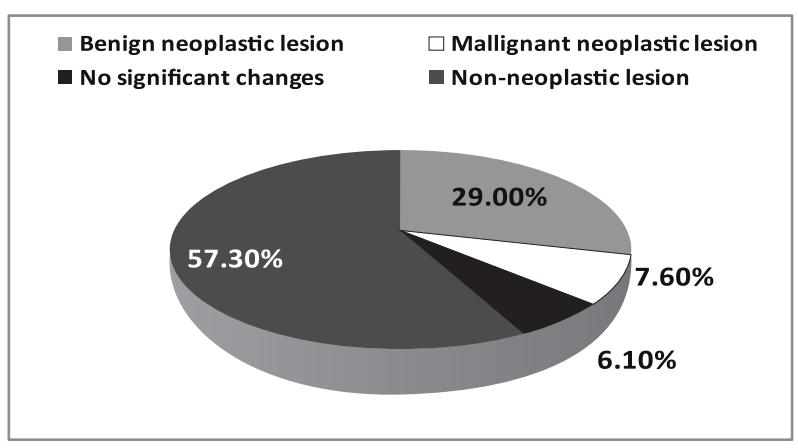

Fig-1: Histopathological changes of colonic mucosal biopsies lesion

Colonic polyps are broadly categorized in non- neoplastic and neoplastic polyps. Out of 118 polyps, 22 cases were non neoplastic (hyperplastic polyps) and 96 were neoplastic polyps. Neoplastic polyps included Tubular adenoma, Tubulovillous adenoma and Villous adenoma. In Fig-2 shows among the neoplastic lesions, most common is the tubular adenoma $57.85 \%$, followed by tubulovillous adenoma $13.22 \%$, villous adenoma $8.26 \%$. Among the malignant lesion, adenocarcinoma was $15.71 \%$ and carcinoid $4.13 \%$.

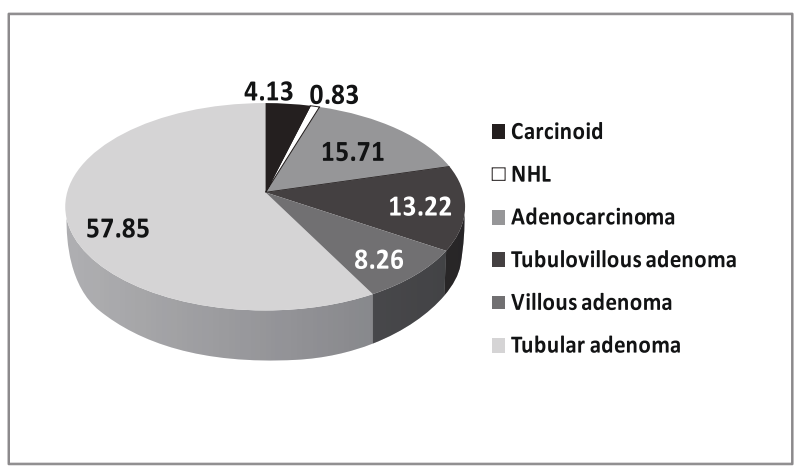

Fig-2: Distribution of colorectal neoplastic lesion $(n=121)$
Among the malingnant lesion adenocarcinoma were more commonly present in sigmoid colon (08 cases) followed by rectum (05 cases).Thus adenocarcinoma showed a left sided predilection. Most of the carcinoid is in the appendix (Table-IV).

Table-IV: Site distribution of malignant neoplastic lesions $(n=25)$

\begin{tabular}{|l|c|c|c|}
\hline Site & Adenocarcinoma & Carcinoid & 0thers \\
\hline Caecum & 02 & & 01 \\
\hline Appendix & 01 & 03 & \\
\hline Ascending colon & 02 & - & \\
\hline Transverse colon & 01 & - & \\
\hline Sigmoid colon & 08 & - & \\
\hline Rectum & 05 & 02 & \\
\hline Total & $\mathbf{1 9}$ & $\mathbf{0 5}$ & $\mathbf{0 1}$ \\
\hline
\end{tabular}

Out of 25 malignant lesions, most common malignant tumour was moderately differentiated adenocarcinomas followed by well differentiated adenocarcinoma and carcinoid (Table-V).

Table-V: Categorization of malignant tumour $(n=25)$

\begin{tabular}{|l|c|}
\hline Categories of malignant tumour & n \\
\hline Well differentiated adenocarcinoma & 05 \\
\hline Moderate differentiated adenocarcinoma & 09 \\
\hline Poorly differentiated adenocarcinoma & 02 \\
\hline Mucinous adenocarcinoma & 02 \\
\hline Signet ring adenocarcinoma & 01 \\
\hline Non Hodgkin Lymphoma & 01 \\
\hline Carcinoid tumour & 05 \\
\hline Total & $\mathbf{2 5}$ \\
\hline
\end{tabular}

\section{Discussion}

In present study (Table-II), Out of 330 biopsies, $63.33 \%$ were non-neoplastic and $36.66 \%$ biopsies were neoplastic lesion. These finding are similar to other studies where non-neoplastic lesions were detected more than the neoplastic lesions $(66.3 \%$ vs. $28.9 \%, 61.3 \%$ vs. $38.7 \%)^{12,13}$. Among all non-neoplastic lesions, $53.97 \%$ biopsies comprised of chronic non specific colitis, $24.34 \%$ were IBD and others made up of $21.69 \%$ cases. But colitis was found in other previous study series where it was $47.3 \%$ and $38.3 \%$ biopsies $^{12,14}$. From this study, it was observed 
an incidence of $13.94 \%$ cases of IBD among all lesions $(n=330), 9.7 \%$ being Ulcerative colitis (UC) and $4.24 \%$ Crohn's disease (CD). Wool rich and colleagues ${ }^{15}$ showed that low grade dysplasia (LGD), like HGD, is also predictive factor of future carcinoma. Their study showed that $18 \%$ of those with LGD progressed to carcinoma within an average of 6.3 years. Therefore, it is important to document presence of dysplasia in $U C$ and $C D$, which will determine the course of treatment in these patients. Rangaswamy $\mathrm{R}$ et $\mathrm{al}^{16}$ observed that IBD comprised $24.4 \%$ of non-neoplastic lesions in their study. Karve $\mathrm{SH}$ et $\mathrm{al}^{17}$ in their study observed $11 \%$ cases of Ulcerative colitis and $4 \%$ cases of Crohn's disesase. They also identified dysplasia in $62 \%$ cases of UC, $72 \%$ showing low grade dysplasia(LGD) and $28 \%$ was high grade dysplasia (HGD). In the present study, $65 \%$ cases of UC showed variable degree of dysplasia, among them $70 \%$ cases of LGD and the other $30 \%$ cases of HGD. These patients require follow up and different modalities of treatment. Thus our observations were comparable to these studies.

In the present study, colonic biopsies enabled to identify histopathological causes of unexplained chronic diarrhoea in nearly $43.33 \%$ of a sample of patients whom colonoscopic findings were normal, approximately $20.60 \%$ of them could be treated by an appropriate therapy or surgical removal based on the findings of UC, CD, hyperplastic polyps, adenomatous polyp, adenocarcinoma and different types of colitis like collagenous colitis, lymphocytic colitis etc. Adenomas are the precursor conditions of colorectal carcinoma Most common site for adenomatous polyps was sigmoid colon followed by rectum. Konishi $\mathrm{F}$ et al ${ }^{18}$ in their study of colorectal adenomas found that $81 \%$ were tubular adenomas while only $19 \%$ were villous and tubulo-villous type. Tony $\mathrm{J}$ and Harish $\mathrm{K}$ et $\mathrm{al}^{19}$ found that in Southern India adenomatous polyps were the most common polyps $(79.8 \%)$ in the age group of 23-82 years with M:F ratio of 2.5:1. They also found severe dysplasia in $12 \%$ of tubular adenomas and $43 \%$ of villous adenomas which is consistent with this study. In high grade dysplasia patients requires more attention as colectomy may required. Other adenomas require only polypectomy and further follow up in future.

In this study malignancies were seen only in $7.5 \%$ of all biopsies. Majority of the malignant cases were males $(60 \%)$. The most common site of occurrence of the malignant tumors was sigmoid colon followed by rectum. The number of malignant lesion are less than other different study series of Sudarshan et $\mathrm{al}^{20}$ and Laishram RS et al ${ }^{21}$. It was evident that due to health awareness and frequent medical checkup and early biopsy taken from suspected lesion that reduced the number of malignant lesion in this region.

\section{Conclusion}

The histomorphological evaluation of colorectal biopsies has a wide spectrum, ranging from infectious conditions, inflammatory disorders and precancerous lesions to colorectal malignancies. This study emphasizes the need for early diagnosis of these diseases through histopathology which when correlated clinically will help the surgeon/clinician to implement the appropriate treatment and improve the survival of the patient. Patients with normal colonoscopy as in present study that contributed the more specific diagnosis like lymphocytic colitis, eosinophilic colitis, ulcerative colitis and pseudo-membranous colitis. Moreover with the early histomorphological diagnosis by detecting the precancerous lesion, like Ulcerative colitis, adenomatous polyp, patient can get rid of developing cancer and thereby saved life.

\section{References}

1. Finlay AM, Prithi B. Colonoscopy and biopsy. Gastroenterology 1997; 11(1):65-82.

2. Badary DM, Hafez MZ. Role of Mucosal Colonic Biopsy in Patients with Chronic Unexplained Diarrhoea who their Colonoscopy is Normal. Molecular biology 2017; 2(6):1-4.

3. Bowles CJ, Leicester R, Romaya $C$ et al. A prospective study of colonoscopy practice in the UK today: Are we adequately prepared for national colorectal cancer screening tomorrow? Gut 2004; 53:277-83.

4. Nossa FLC, Paula NBLBB. Diagnostic and therapeutic evaluation of colonoscopic biopsy. Revista Brasileira de Coloproctologia 1999; 19:168-71.

5 Kagueyama FM et al, Importance of biopsies and histological evaluation in patients with chronic diarrhea and normal colonoscopies. ABCD Arq Bras Cir Dig 2014; 27(3):184-7.

6. Dube AK, Cross SS, Lobo AJ. Audit of the histopathological diagnosis of non-neoplastic colorectal biopsies: Achievable standards for the diagnosis of inflammatory bowel disease. J Clin Pathol 1999; 51(5):378-81.

7. Berre NL, Heresbach D, Kerbaol M et al. Histological discrimination of Idiopathic Inflammatory Bowel Disease from other types of colitis. J Clin Pathol 1995; 48(8):749-53.

8. Fenoglio-Preiser CM, Noffsinger AE, Stemmerman GN et al. Gastrointestinal pathology An Atlas and Text. 3rd ed. Philadelphia: Lippincot Williams and Wilkins 2008; 14:899-1036.

9. Park DI, Kang MS, Oh SJ et al. Her-2/neu over expression is an independent prognostic factor in colorectal cancer. Int $\mathrm{J}$ Colorectal Dis 2007; 22:491-7.

10. Cherneck and Berger. In: Laboratory test and diagnostic procedure. 5th ed; 2008:65-6.

11. Rajbhandari $M$, Karmacharya $A$, Khamal $K$ et al. Histomorphological profile of colonoscopic biopsies and pattern of colorectal carcinomas in Kavre district. Kathmandu Univ Med J 2013; 43(3):196-200.

12. Qayyum A, Sawan AS. Profile of colonic biopsies in King Abdul Aziz University Hospital, Jeddah. J Park Med Assoc 2009; 59(9):608-11.

13. Winawer SJ, Leidner SD, Haidu SI. Colonoscopic biopsy and cytology in the diagnosis of colon cancer. Cancer 1978; 42(6):2849-53. 
14. Dickinson RJ, Gilmour HM, McClelland DB. Rectal biopsy in patients presenting to an infectious unit with diarrhoeal disease. Gut 1979; 20(2):141-8.

15. Woolrich AJ, DaSilva MD, Korelitz BI. Surveillance in the routine management of ulcerative colitis: The predictive value of low-grade dysplasia. Gastroenterology 1992; 103:431-8.

16. Rangaswamy R, Sahadev R, Suguna BV et al. Clinico-colonoscopic and Histomorphological Spectrum of Colonic Diseases in an Academic Tertiary Care Centre. Journal of Evolution of Medical and Dental Sciences 2014; 6(3):1-9.

17. Karve SH, Vidya K, Shivarudrappa AS et al. The Spectrum of colonic lesions: A Clinico-pathological study of colonic biopsies. Indian Journal of Pathology and Oncology 2015; 2(4):189-209.
18. Konishi F, Morson BC. Pathology of colorectal adenomas. A colonoscopic survey. J Clin Pathol 1982; 35(8):830-41.

19. Tony J, Harish K, Ramachandran TM et al. Profile of colonic polyps in a Southern Indian population. Indian J Gastroenterol 2007; 26(3):127-29.

20. Sudarshan V, Hussain N, Gahine R et al. Colorectal cancer in young adults in a tertiary care hospital in Chattisgarh, Raipur. Indian Journal of Cancer 2013; 50(4):337-40.

21. Laishram RS, Kaiho N, Shimray R et al. Histopathological Evaluation of Colorectal Carcinomas status in Manipur, India. International Journal of Pathology 2010; 8(1):5-8. 